\title{
Prevalence, pathogenesis, therapy, and prevention of cardiovascular events in patients with community-acquired pneumonia
}

\author{
Charles Feldman ${ }^{1,2,4^{*}}$ and Ronald Anderson ${ }^{3}$
}

\begin{abstract}
It is now well recognised that cardiac events occur relatively commonly in patients with acute community-acquired pneumonia. While these events are more frequent in patients with underlying risk factors-such as those with underlying chronic cardiovascular and respiratory comorbidities, the elderly, and in nursing home residents - they also occur in patients with no underlying risks other than severe pneumonia. Recent research elucidating the underlying pathogenic mechanisms related to these cardiac events has indicated a probable role for platelet activation, which is possibly exacerbated by pneumolysin in the case of pneumococcal infections. This, in turn, has resulted in the identification of possible therapeutic strategies targeting platelet activation, as well as the cardio-toxic activity of pneumolysin. These issues represent the primary focus of the current review.
\end{abstract}

Keywords: Macrolides, Platelets, Pneumococcus, Pneumolysin, Statins, Pneumococcal vaccines

\section{Background}

For a considerable period of time, investigators have been reporting on the occurrence of cardiac events in patients with acute respiratory tract infections, including community-acquired pneumonia (CAP) [1, 2]. Among these cardiac events are acute coronary syndromes (acute myocardial infarction [AMI]), acute or worsening cardiac arrhythmias and new or worsening congestive heart failure (CHF) [2]. The features of the association between acute coronary events and arrhythmias and CAP appear to fulfill the criteria for causality-namely, that pneumonia is a cause of these events; whereas, in the case of CHF, it appears the cause-effect relationship may be bidirectional [2]. More recent studies are beginning to give insight into the magnitude of this problem, also indicating that these events tend to be particularly common early on during the course of CAP, and also

\footnotetext{
* Correspondence: charles.feldman@wits.ac.za

${ }^{1}$ Division of Pulmonology, Department of Internal Medicine, Charlotte Maxeke Johannesburg Academic Hospital, Johannesburg, South Africa

${ }^{2}$ Faculty of Health Sciences, University of the Witwatersrand, Johannesburg,

South Africa

Full list of author information is available at the end of the article
}

tend to be more common in patients with certain risk factors, including older age, nursing home residence, pre-existing cardiovascular disease, and in more severe pneumonia [2]. Nevertheless, it is important to recognise that in up to $50 \%$ of cases with CAP in which acute cardiac complications occur, there has been no prior history of overt chronic cardiac disease [3].

It is interesting to reflect on the fact that in patients with CAP, $50 \%$ of the mortality within the first month is due to comorbidities and not directly due to the consequences of CAP (e.g. respiratory failure or sepsis), and that cardiovascular diseases are also among the main causes of death following a CAP episode $[4,5]$. Furthermore, cardiovascular events (CVEs) are recognised to be the primary causes of clinical failure in patients with CAP and should be actively looked for in patients not responding to standard medical care [6]. Importantly, it is now recognised that acute cardiac events occurring during the course of CAP are associated with negative impacts on both short-term and long-term outcomes $[2,6]$. This article will review the clinical studies of cardiac events in patients with CAP, describe the likely pathogenic mechanisms involved in this interaction, and discuss possible 
therapeutic and preventative strategies to manage these events, particularly in pneumococcal CAP.

\section{Clinical studies \\ Acute infections and the onset of acute coronary syndromes}

In 1984, Spodick and colleagues [7] prospectively investigated 150 patients hospitalised with AMI and an equivalent number of age-, sex- and date-of-admission-matched controls. They noted that there was an increased risk (odds ratio $[\mathrm{OR}] 2.2 ; p<0.02$ ) of the occurrence of minor acute respiratory symptoms in the patients with AMI compared with the controls, and suggested that further investigations should be undertaken to determine if there was a pathogenic relationship between acute respiratory symptoms, considered likely to be of viral origin, and the onset of AMI. Over many subsequent years, the association between acute infections, most commonly respiratory infections, but also Staphylococcus aureus bacteraemia, urinary tract infections and gastroenteritis, and the occurrence of acute coronary syndromes has been documented [1].

\section{CAP and acute cardiac events}

Seedat and colleagues [8] undertook one of the first studies investigating acute cardiac events in hospitalised patients with acute CAP. The authors prospectively studied consecutive patients with CAP who had no prior or underlying cardiorespiratory illnesses. In addition to recording demographic, clinical, microbiological, laboratory, and outcome data, they also performed electrocardiographic (ECG) and echocardiographic investigations and measured serum enzyme, including cardiac enzyme levels (creatinine kinase [CK], CK-MB fraction, and lactate dehydrogenase $[\mathrm{LDH}]$ ). A number of ECG changes were documented, which returned to normal after a mean of 2 days in survivors. The so-called S1, Q3, T3 pattern on ECG was associated with CK-MB leak, hypoxia and a high Simplified Acute Physiology Score (SAPS). The presence of $\mathrm{P}$ pulmonale, right axis deviation and clockwise rotation correlated with hypoxia and high SAPS score. Clockwise rotation also correlated with raised serum LDH and CK-MB levels and high pulmonary artery pressures. The overall patient mortality was $10.8 \%$ and a number of negative prognostic factors were documented. While there was no association between the ECG changes and mortality, raised LDH, CK and CK-MB levels correlated, among other factors, with need for intensive care unit (ICU) admission and mortality.

Ramirez and colleagues [9] undertook a retrospective observational study of 500 consecutive cases with CAP enrolled into the Community-Acquired Pneumonia Organization (CAPO) study. On hospital admission, AMI was documented in 29/500 (5.8 \%) patients, including 13/86 (15\%) patients with severe CAP, and AMI was subsequently documented during hospitalisation in 13/65 (20\%) patients who experienced clinical failure. Significant associations between AMI and Pneumonia Severity Index (PSI) $(p=0.05)$ and clinical failure $(p=0.04)$ were noted after risk adjustment. The authors concluded that in patients with CAP experiencing clinical failure, AMI should be considered as a possible aetiology. Other investigators have confirmed that acute cardiac events [10] and both cardiovascular and cerebrovascular events [11] are common and are associated with significant morbidity and mortality in patients with CAP.

Perry et al. [12] examined a cohort of 50,119 subjects extracted from databases of the Department of Veterans Affairs (VA) from the period October 2001 to September 2007. The patients, of whom $98 \%$ were males, had a mean age of 77.5 years (standard deviation 6.7 years), and the 90-day incidence of CVEs was $1.5 \%$ for AMI, 10.2 \% for CHF, $9.5 \%$ for arrhythmia, $0.8 \%$ for unstable angina, and $0.2 \%$ for stroke, with most events occurring during hospitalisation. The authors suggested that CVEs may play a significant role in CAP patient mortality and that research was needed to determine whether appropriate interventions could reduce the number of these CVEs.

Corrales-Medina et al. [13] studied 1,343 inpatients and 944 outpatients with CAP for 30 days after their presentation. They noted cardiac events (defined as new or worsening CHF, new or worsening arrhythmia, or AMI) in 358 (26.7\%) of inpatients and 20 (2.1\%) of outpatients. More than half of these events were documented in the first $24 \mathrm{~h}$, and the factors that were particularly associated with their diagnosis included older age, nursing home residence, pre-existing cardiovascular conditions and indicators of pneumonia severity. These authors also considered that further studies on risk stratification of CAP patients for these complications and strategies for their prevention and treatment need to be undertaken.

\section{Risk stratification for acute cardiac events/cardiac complications in patients with CAP}

Viasus and colleagues [3] undertook a study to investigate risk stratification for these acute cardiac events and their prognosis. This was a prospective observational study of a cohort of 3,921 hospitalised adults with CAP, in whom a logistic regression analysis was performed to document predictors for these acute cardiac events and their mortality. Overall 315 (8\%) of these patients had $\geq 1$ acute events during hospitalisation and multivariate analysis documented a number of risk factors for these events, which were used to develop a prognostication rule that had an area under the receiver operating characteristic curve of 0.73 (95\% confidence interval [CI] 0.70-0.76). The case fatality rate was significantly higher in patients who had an acute cardiac event $(19.4 \%)$ than in patients 
who did not have such an event $(6.4 \% ; p<0.001)$. The authors concluded that such a rule could be used to identify CAP patients at high risk of cardiac complications.

Other investigators have sought to develop clinical rules for risk stratification in patients hospitalised with CAP [14]. In this study, 2 cohorts of patients were selected, which represented the derivation and validation cohorts. A point score system was developed from the derivation cohort which, when applied to the validation cohort, had good discrimination and outperformed the PSI in predicting cardiac complications.

Aliberti and colleagues [15] studied the prevalence, clinical characteristics, risk factors and impact on outcome of AMI versus other CVEs in patients with CAP. They documented that hospital mortality was higher in patients with AMI in comparison to those who had other CVEs and suggested that this should be considered when planning interventional studies.

\section{Impact of prior therapy on risk of cardiac events in patients with CAP}

Using the Department of VA administrative database, Soto-Gomez et al. [16] studied hospitalised CAP cases $\geq 65$ years, in which the patients received antibiotics within $48 \mathrm{~h}$ and had no prior diagnosis of a cardiac arrhythmia. They documented that 3,919/32,689 (12 \%) patients developed cardiac arrhythmia within 90 days of admission. Increased age, history of CHF, and need for mechanical ventilation or vasopressors were significantly associated with the occurrence of an arrhythmia and, even after adjustment for confounders, incident cardiac arrhythmias were associated with increased 30-day and 90-day mortality. However, beta-blocker use was associated with a decreased risk of arrhythmia (OR 0.92 [95\% CI 0.85-0.99]). Other investigators documented that 376/ 3,068 (12\%) hospitalised patients with CAP had a CVE and, while hyperlipidaemia, more severe pneumonia and S. aureus and Klebsiella pneumoniae pneumonias were associated with an increased risk, statin use was associated with a decreased risk [17]. Both these investigators suggested that studies of cardioprotective therapies in patients with CAP should be undertaken to determine if they are able to attenuate cardiac risks $[16,17]$.

\section{Long-term cardiovascular complications of CAP}

More recently, a number of investigators have studied long-term cardiovascular complications of CAP [18-21]. In one investigation adult patients with CAP initially hospitalised in a tertiary hospital were followed up for 1 year, post-discharge [18]. Overall, 93/1,284 (7.2 \%) patients died within 1 year of hospital discharge (68 [73.1\%] in the first 6 months). The main reasons for mortality were infectious diseases, mainly pneumonia, and acute CVEs. A number of risk factors were noted, including chronic obstructive pulmonary disease, diabetes, cancer, and dementia, which could help identify cases at high risk of long-term mortality. Another study documented cardiac complications (sometimes more than one) in 55/310 (18 \%) hospitalised CAP patients, which included AMI or a new episode of atrial fibrillation in 32 and 30 patients, respectively [19]. However, during the follow-up, 89 patients died $(51 \%$ of whom had experienced an in-hospital cardiac complication, versus $26 \%$ who had not; $p<0.001$ ); in addition, 73 had a CVE (47\% of patients who had experienced an inhospital cardiac event, versus $19 \%$ who had not; $p<$ 0.001). Among other factors, in-hospital cardiac events were significantly associated with both overall mortality and CVEs during follow-up. A third study in elderly patients with CAP ( $\geq 65$ years) [20] documented the occurrence of new onset of heart failure in both the intermediate and long-term (even after 5 years) following hospitalisation, which had not been present on hospital admission. These same authors confirmed in an additional study [21] that hospitalisation for CAP is associated with both short-term and long-term risk of cardiovascular disease and while the risk of cardiovascular disease was greatest in the first year following hospitalisation, it remained higher than in controls for up to 10 years of follow-up.

Currently, a study is being undertaken to document whether various diverse inflammatory and immune response mediators may be used as markers of both short-term and long-term (1 year) occurrence of cardiovascular disease and mortality [22].

\section{Non-cardiac complications in patients with AMI}

Other investigators, in contrast, have studied patients with AMI and looked for the occurrence of acute, lifethreatening and/or significant non-cardiac events that were present on hospital admission of these patients [23]. Such events occurred in approximately one-third of patients with AMI. Of the 1,145 patients studied, pneumonia was noted in $7.2 \%(n=82)$, which were classified as life-threatening in $1.5 \%(n=17)$ and significant in $5.7 \%(n=65)$. This study was undertaken early on in 2006 and, given what we have subsequently learned about the occurrence of cardiac events in patients with pneumonia, it would be interesting to speculate whether the primary event in at least some of these cases with AMI and severe pneumonia may have been the pneumonia itself.

\section{Pneumococcal pneumonia and acute cardiac events}

In 2007, Musher and colleagues [24] published the first study investigating the possible association between pneumococcal pneumonia and acute cardiac events. This was a study undertaken over a 5-year period 
(2001-2005) aimed at identifying hospitalised patients with pneumococcal pneumonia who developed AMI, significant arrhythmia (namely atrial fibrillation or ventricular tachycardia), or new onset or worsening of CHF. Overall, 33/170 (19.4\%) patients had one or more of these cardiac events: 12 had AMI ( 2 also had arrhythmia and 5 had new or worsening CHF), 8 had an arrhythmia (6 also had new onset CHF) and 13 had new or worsening CHF. There was a significantly higher mortality in those patients with pneumococcal pneumonia who had an acute cardiac event compared with those that did not $(p<0.008)$

\section{Cardiac complication in patients with CAP: systematic review and meta-analysis}

Corrales-Medina et al. [25] undertook a systematic review and meta-analysis to document the incidence of major cardiac complications within 30 days in patients diagnosed with CAP in order to determine the magnitude of the problem. Among the 17 articles (68 \%) that had reported on in-patient cohorts of CAP, data extracted from appropriate studies indicated that incidence rate of overall cardiac complications was $17.7 \%$, heart failure was $14.1 \%$ (range 7-33\%), acute coronary syndromes was $5.3 \%$ (range 1-11\%) and cardiac arrhythmias was $4.7 \%$ (range 1--11\%). Major conclusions from this analysis were that cardiac complications were common in patients with CAP and needed to be better appreciated by physicians and patients alike, with early recognition and appropriate management. Furthermore, the investigators indicated the need for a better understanding of pathogenic mechanisms, of risk factors, and of the impact of these cardiac events on patient outcome. In addition, as indicated by these and other investigators, there needs to be a better understanding of interventions to treat these complications (e.g. with the use of cardioprotective medications), as well as to prevent them (e.g. with use of influenza virus and pneumococcal vaccination) [26]. Possible therapeutic and preventative strategies, preceded by a brief overview of current concepts in pathogenesis including the role of pneumolysin in CAP-associated CVEs, are discussed in more detail below.

\section{Pathogenic mechanisms of CAP-associated CVEs The role of platelets}

Mirsaeidi et al. [27], recognising that platelets were inflammatory cells that played an important role in host antimicrobial defences, undertook a study to evaluate the association between abnormalities of the platelet count and 30-day mortality in patients with CAP. These investigators documented that the occurrence of either thrombocytopaenia or thrombocytosis were associated with in-hospital mortality in patients with CAP and that these abnormalities of the platelet count were better predictors of outcome than similar abnormalities of the leukocyte count.

Recent and novel insights into the pathogenesis of CAP-associated CVEs have been provided by the findings reported in a study by Cangemi et al. [28]. This study, which did not distinguish between viral and bacterial CAP, confirmed the high risk for development of myocardial infarction, which peaked within 2 days of hospitalisation. Notwithstanding disease severity and heart ejection fraction, significant predictors of myocardial infarction included elevated concentrations of the circulating biomarkers of platelet activation, soluble CD40 ligand, P-selectin (CD62P) and thromboxane B2 (a surrogate for thromboxane A2), as well as the mean platelet volume [28]. The contention that platelet activation plays a pivotal role in orchestrating inflammatory events which trigger, or more likely exacerbate, vascular damage and dysfunction is supported by the steadily increasing recognition of the critical role played by these cells in mediating inflammatory and immune responses [29-33].

Pro-inflammatory mechanisms by which platelet activation may contribute to the pathogenesis of bacterial CAP in particular have recently been reviewed elsewhere [30] and are briefly considered and updated here. The most significant of these is activation and aggregation of platelets by bacteria and their products such as cell-wall components (lipoteichoic acids/peptidoglycans/endotoxins), DNA, and toxins such as pneumolysin and staphylococcal $\alpha$-haemolysin $[34,35]$. These, in turn, interact with and activate Toll-like receptors (TLRs) and other types of pathogen-recognition receptors that are expressed on platelets $[29,30,36]$. In this context, it is, however, noteworthy that a role for platelet TLRs in sepsis-mediated endothelial dysfunction has been challenged based on data derived from an experimental model of Gram-negative sepsis [37].

Bacteria, specifically those belonging to the Staphylococcus and Streptococcus genera, have also been reported to mediate platelet activation by a complex and unusual mechanism involving the interaction of these microorganisms with platelet factor 4 (PF-4) present in platelet $\alpha$-granules [38]. The resultant complex binds to immunoglobulin G FcRIIA receptors, resulting in activation of the platelet pro-thrombotic, fibrinogen-binding integrin, GPIIb/IIIa [38].

In addition to the aforementioned mechanisms, we have recently observed that the major protein virulence factor of the pneumococcus, pneumolysin, activates the production of platelet-activating factor (PAF) by human neutrophils in vitro. These effects, which were observed at pathologically relevant concentrations of the toxin, were dependent on its cholesterol-binding, pore-forming 
activity and unrelated to interaction with TLR4 [39]. In this context, it is noteworthy that PAF has been reported to contribute significantly to pneumolysin-induced lung injury in a murine model of experimental infection [40]. We have also observed that pneumolysin, also at pathologically relevant concentrations, activates platelets directly, according to upregulated surface expression of the adhesion molecule CD62P, a constituent of platelet $\alpha$-granules. This pro-adhesive mechanism, which favours the binding of platelets to both neutrophils and vascular endothelium, was also dependent on the pore-forming activity of pneumolysin [41].

These various mechanisms of platelet activation not only favour homotypic aggregation resulting in the formation of platelet clusters, but also heterotypic aggregation of these cells with neutrophils and vascular endothelium. In this setting, activated platelets act as bridges promoting neutrophil clusters, as well as binding of neutrophils to vascular endothelium mediated by CD62P and other pro-adhesive mechanisms [30, 32, 42]. If poorly controlled, systemic inflammatory mechanisms involving platelets, neutrophils and vascular endothelium predispose to endothelial damage and dysfunction, promoting microvascular damage and coagulation [31].

Potential mechanisms of endothelial damage, resulting in exposure of sub-endothelial collagen and von Willebrand factor, include exposure to cytotoxic neutrophil-derived reactive oxygen species and proteases. In addition, activated platelets have been reported to induce the formation of neutrophil extracellular traps (NETs) at sites of plaque rupture in vivo [43]. NETs contribute to atherothrombosis by several mechanisms. These include the cytotoxic actions of their histone constituents on endothelium, as well as expression of functional, neutrophil-derived tissue factor [44].

\section{Effects of pneumolysin}

Pneumolysin is increasingly implicated in the pathogenesis of life-threatening acute cardiac complications in CAP, albeit based on data derived from experimental animal models. Brown et al. [45] have reported that experimental invasive pneumococcal disease (IPD) in mice and rhesus macaques was associated with myocardial damage and formation of cardiac microlesions. Translocation of the pneumococcus into the myocardium appeared to be dependent on the pneumococcal adhesins, choline-binding protein $\mathrm{A}$ and phosphorylcholine, while microlesion formation was mediated by pneumolysin [45]. Similar microlesions were detected in cardiac sections from patients with fatal IPD [45]. The authors concluded "that the microlesions and the scarring that occurs thereafter may explain why adverse cardiac events occur during and following IPD" [45].

Essentially similar findings have been reported by Alhamdi et al. [46]. The authors, who also used a murine model of IPD, observed that infection with pneumolysinexpressing pneumococci, but not with strains deficient in the toxin, resulted in significant elevations in circulating cardiac troponins and myocardial injury [46]. These injurious effects on the myocardium were mimicked by intravenous administration of recombinant pneumolysin, but not by a mutant toxin devoid of pore-forming activity, and were attenuated by co-administration of pneumolysinsequestering liposomes [46]. Mechanistically, exposure of murine cardiomyocytes to sublytic concentrations of the toxin resulted in intense calcium influx and overload followed by membrane depolarisation [46], as previously reported for human neutrophils [47]. These disruptive effects of the toxin on cardiomyocytes were associated with a "progressive reduction in intracellular calcium transient amplitude, a key determinant of contractile force" [46].

Given its dual mechanism of mediation of cardiac dysfunction-firstly, direct damage to cardiomyocytes; and secondly, pro-inflammatory, pro-thrombotic actions involving activation of platelets and neutrophils and damage to vascular endothelium-pneumolysin appears to be a priority target in the prevention of CAP-associated CVEs.

\section{Treatment and/or prevention of CAP-associated CVEs}

Three potential strategies will be considered here: (i) adjunctive anti-platelet pharmacological agents; (ii) strategies targeting pneumolysin; and (iii) pneumococcal immunisation.

\section{Anti-platelet strategies}

These have been covered extensively in recent reviews [31, 48] and will be considered briefly here. Agents which target platelet activation fall into several categories, targeting both mediators of activation and their receptors, and include, but are not limited to, the following:

- inhibitors of production of thromboxane $\mathrm{A}_{2}$

- antagonists of thromboxane $\mathrm{A}_{2}$ receptors

- antagonists of ADP-activated P2Y12 receptors

- antagonists of thrombin-activated proteinaseactivated receptor 1

- GPIIb/IIIa inhibitors.

Given the relatively recent appreciation of the role of platelet activation in the pathogenesis of CAP-associated CVEs, it is understandable that no compelling supportive data on the preventive potential of anti-platelet therapies in this setting currently exists. However, of the various categories of anti-thrombotic agents, aspirin, which decreases the production of thromboxane $A_{2}$ via its inhibitory effects on cyclooxygenase-1, represents a 
relatively safe and inexpensive option in the setting of prevention of CAP-associated CVEs.

In this context, it is noteworthy that the study alluded to earlier by Cangemi et al. [28] describing the association between CAP, platelet activation and CVEs, failed to detect a protective effect of aspirin administered at a daily dose of $100 \mathrm{mg}$ on the occurrence of myocardial infarction. The authors attributed the lack of benefit to an inadequate dose of aspirin. In a subsequent prospective study in which a larger number $(n=1,005)$ of elderly hospitalised patients with CAP was recruited, these same authors investigated the effect of administration of aspirin (100 mg daily before and during hospital admission) on the 30-day mortality rate and overall incidence of non-fatal CVEs [49]. During the follow-up period, $16.2 \%$ of patients died: $19 / 390(4.9 \%)$ in the group of aspirin-users and $144 / 615(23.4 \% ; p<0.001)$ in the group of non-users, with a hazard ratio for total mortality of $2.07(p=0.029)$ [49]. Non-fatal CVEs occurred in $7 \%$ of patients, $4.9 \%$ and $8.3 \%$ of whom were aspirinusers and non-users, respectively (OR 1.77; $p=0.04$ ).

Other studies, one focused on CAP [50], others on acute lung injury (ALI)/acute respiratory distress syndrome (ARDS) [51-53] have reported significant benefit of pre-hospitalisation administration of anti-platelet therapies, including aspirin, on various outcomes such as requirement for intensive care treatment, length of hospital stay, incidence of ALI/ARDS, and mortality. These findings were not, however, confirmed in a large multicentre, international observational study $(n=3,855$ patients) focused on the potential benefit of prehospitalisation administration of aspirin on development of ALI following hospital admission [54]. Although univariate analysis revealed a reduced incidence of ALI in patients receiving aspirin therapy (OR $0.65 ; p=0.010)$, this protective effect was attenuated using propensity score analysis (OR 0.70; $p=0.072$ ) [54]. Nonetheless, the authors conceded that prospective intervention trials were justified. In this context, a recently published study [55], albeit involving a relatively small number of patients with ARDS $(n=202)$ admitted to a single medical and surgical ICU over an 18-month period, is noteworthy. The authors observed that administration of aspirin pre-hospitalisation and during ICU stay was associated with a significant reduction in mortality (OR $0.38 ; p=0.04)$ [55].

Although aspirin in particular, and possibly other antiplatelet therapies show promise in the prevention of the major cardiovascular and pulmonary complications of CAP, there is a clear need for stringently controlled, definitive intervention trials in this setting.

\section{Strategies targeting pneumolysin}

Given the well-recognised involvement of pneumolysin in the pathogenesis of pneumococcal CAP and its major pulmonary complications $[40,56,57]$, together with increasing evidence implicating the toxin in the aetiology of CVEs associated with this condition, pneumolysin is clearly a priority target for therapeutic intervention. Two types of strategy exist: firstly, the use of agents, specifically macrolide and macrolide-like antibiotics, which target production of pneumolysin by the pneumococcus; and secondly, agents which attenuate the cytotoxic and pro-inflammatory activities of the toxin, specifically statins and intravenous cholesterol-risk liposomes.

\section{Macrolides}

Unlike bactericidal antibiotics, such as beta-lactams, which potentiate the release of pneumolysin [58], macrolides, via their predominantly bacteriostatic inhibitory effects on protein synthesis, potently suppress the production of the toxin by the pneumococcus. These inhibitory effects of macrolides on the production of pneumolysin, which are evident at sub-inhibitory concentrations of these agents $[59,60]$ even in the setting of macrolide resistance [61], may underpin their utility as adjuncts to beta-lactams in the treatment of severe pneumococcal disease [58, 62].

\section{Statins}

Statins, almost exclusively in the setting of prehospitalisation administration, have been reported in a number of studies to reduce CAP-related mortality and to protect against the development of CAP [reviewed in 31]. In the case of pneumococcal CAP, statins, specifically simvastatin, have been reported to attenuate the harmful activities of pneumolysin. Apart from protecting isolated human brain microvascular endothelial cells [63] and airway epithelial cells [64] against the cytotoxic actions of pneumolysin, simvastatin has also been found to reduce mortality in a murine sickle-cell disease model of experimental pneumococcal infection [63]. While these activities of simvastatin appear to be related to interference with pneumolysin/membrane cholesterol interactions, it is also noteworthy that statins possess alternative anti-inflammatory activity unrelated to their membrane cholesterol-lowering activities that target various inflammatory cell types, including platelets [31].

However, as with conventional anti-platelet agents, the potential of statins to target CVEs, as well as pulmonary complications, in patients with recently diagnosed CAP awaits the outcome of stringently controlled intervention trials.

\section{Cholesterol-enriched liposomes}

Intravenous co-administration of penicillin together with liposomes containing high concentrations of cholesterol in particular, as well as sphingomyelin, within $10 \mathrm{~h}$ after experimental infection of mice, has been found to protect against development of septicaemia and mortality in 
comparison with control animals or those treated with penicillin only [65]. The authors attributed the protective effects of the liposomes to sequestration of pneumolysin. Although innovative, the practicality of this approach in the clinical setting is debatable.

\section{Pneumococcal immunisation}

The protective effect of immunisation in the prevention of influenza-associated acute coronary events is well recognised [66-68], suggesting that a similar relationship may exist in the case of pneumococcal polysaccharide vaccine 23 (PPV23), which has been available since 1983 [69]. In this context, it is noteworthy that a large casecontrol study documented a significant decrease of $>50 \%$ in the rate of myocardial infarction in recipients of PPV23, which was evident from 2 years and onwards following administration of the vaccine [70]. More recently, a systematic review and meta-analysis of 11 cohort studies covering the period 2000-2013, which included 332,267 participants, concluded that administration of PPV23 conferred transient protection against both myocardial infarction and cerebrovascular events [71].

These apparently protective effects of PPV23 in the prevention of CVEs have, however, been challenged by the findings of a number of large case-control and population-based cohort studies which failed to confirm protection against AMI, ischaemic stroke, transient ischaemic events and all-cause mortality [66, 67, 72, 73]. In another population-based cohort study of adults presenting with CAP, PPV23 immunisation was associated with a $58 \%$ reduction in acute coronary syndrome events occurring within 90 days of pneumonia [73]. However, sensitivity analyses revealed that the protective effect of PPV23 was most likely attributable to a confounding "healthy vaccinee" effect [74].

Issues which should be considered in future studies designed to evaluate the potential of pneumococcal immunisation in protecting against the development of CVEs, either in the general population or those with CAP include: (i) the confounding potential of prior influenza immunisation, which may result in overestimation of the benefit of pneumococcal immunisation [75]; and (ii) assessment of the benefit of new generation pneumococcal vaccines, specifically pneumococcal conjugate vaccine 13 (PCV13) with improved immunogenicity. While a recent study [76] has documented significant protection against pneumococcal infection in the elderly with the use of PCV13, there have been no studies specifically addressing the impact of PCV13 immunisation on CVEs. However, given the increasing realisation of the probable involvement of pneumolysin in the pathogenesis of CVEs secondary to pneumococcal CAP, the inclusion of an immunogenic pneumolysoid with PCV13 (or a similar polysaccharide conjugate vaccine) may offer maximal benefit [77].
Potential therapeutic and preventative strategies are shown in Table 1.

\section{Conclusion}

The role of CAP in triggering often fatal acute coronary syndromes, almost exclusively in hospitalised patients, is clearly well recognised. The risk for development of cardiac complications is highest soon after diagnosis with about $90 \%$ of these events detected within 7 days and more than half within the first $24 \mathrm{~h}$. Mortality attributable to CAP-related cardiovascular abnormalities may be associated with pre-existing plaque formation (AMI, predominantly silent) or to unrelated causes (arrhythmias), the former being more common. The major risk factors include older age, nursing home residence, severity of CAP, chronic cardiovascular and respiratory comorbidities and smoking. Although most evident in the acute phase of CAP, it is, however, noteworthy that the risk for development of new-onset heart failure in elderly adults previously hospitalised for CAP extends to 1 year, albeit at a lower rate, remaining evident up to 10 years after initial diagnosis. This includes patients who had previously experienced and survived intra-hospital CAPrelated cardiac complications. In this context, CVEs have been reported to account for more than $30 \%$ of deaths at long-term follow-up averaging 1-5.4 years, possibly due to CAP-related exacerbation, as well as possibly persistence of the inflammatory mechanisms described above. Promising therapeutic strategies include those targeting platelet activation, especially aspirin. In the case of pneumococcal CAP, macrolides, statins and cholesterol-loaded liposomes interfere with the production or bioactivity of pneumolysin, while new generation vaccines offer the prospect of prevention.

Table 1 Potential therapeutic/preventative strategies targeting cardiac events in patients with community-acquired pneumonia

- Anti-platelet agents
o inhibitors of production of thromboxane $A_{2}$
o antagonists of thromboxane $A_{2}$ receptors
o antagonists of ADP-activated P2Y12 receptors
o antagonists of thrombin-activated proteinase-activated receptor 1
o GPIIb/Illa inhibitors
- Agents targeting pneumolysin
o macrolides
o statins
o cholesterol-rich liposomes
-Immunisation
o PCV 13 with or without immunogenic pneumolysoid




\section{Search strategy}

The authors searched PubMed (Medline) and Google using the following combinations of topics: CAP and/or community-acquired pneumonia and/or pneumonia AND acute cardiac events and/or acute myocardial infarction and/or arrhythmia and/or cardiac and/or cardiac events and/or cardiac failure and/or cardiovascular and/or cardiovascular events and/or congestive cardiac failure and/or congestive heart failure and/or heart failure and/or neutrophils and/or neutrophil extracellular traps and/or pneumococcus and/or pneumolysin and/or platelets and/or platelet activating factor.

\section{Abbreviations}

ALI, acute lung injury; AMI, acute myocardial infarction; ARDS, acute respiratory distress syndrome; CAP, community-acquired pneumonia; CHF, congestive heart failure; CK, creatinine kinase; CVEs, cardiovascular events; ECG, electrocardiographic; ICU, intensive care unit; IPD, invasive pneumococcal disease; LDH, lactate dehydrogenase; NETs, neutrophil extracellular traps; PCV13, pneumococcal conjugate vaccine 13; PPV23, pneumococcal polysaccharide vaccine 23; TLR, toll-like receptor; VA, Veterans Affairs

\section{Acknowledgements}

Not applicable.

\section{Funding}

CF is supported by the National Research Foundation of South Africa (Incentive Funding for Rated Researchers). The funder had no role in the design of this review, compilation and interpretation of material, decision to publish, or preparation of the manuscript.

\section{Availability of data and materials}

Not applicable.

\section{Authors' contributions}

The authors contributed equally to the planning and writing of the manuscript. All the authors met ICMJE authorship criteria. CF, RA generated and designed the research plan. CF, RA wrote the first draft of the manuscript. CF, RA agree with the manuscript's results and conclusions. CF, RA approved the final version of the manuscript.

\section{Competing interests}

CF has received honoraria for acting on the advisory boards and speaker's bureau of pharmaceutical companies manufacturing and/or marketing macrolide antibiotics and the pneumococcal conjugate vaccine 13 (PCV13) (Abbott, Aspen, Pfizer, Sandoz). RA declares no competing interests.

\section{Consent for publication}

Not applicable.

\section{Ethics approval and consent to participate}

Not applicable.

\author{
Author details \\ ${ }^{1}$ Division of Pulmonology, Department of Internal Medicine, Charlotte \\ Maxeke Johannesburg Academic Hospital, Johannesburg, South Africa. \\ ${ }^{2}$ Faculty of Health Sciences, University of the Witwatersrand, Johannesburg, \\ South Africa. ${ }^{3}$ Institute for Cellular and Molecular Medicine, Department of \\ Immunology, Faculty of Health Sciences, University of Pretoria, Pretoria, \\ South Africa. ${ }^{4}$ Department of Internal Medicine, University of the \\ Witwatersrand Medical School, 7 York Road, Parktown, 2193 Johannesburg, \\ South Africa.
}

Received: 19 November 2015 Accepted: 4 July 2016 Published online: 21 July 2016

\section{References}

1. Corrales-Medina VF, Madjid M, Musher DM. Role of acute infection in triggering acute coronary syndromes. Lancet Infect Dis. 2010;10:83-92. PMID:20113977, http://dx.doi.org/10.1016/S1473-3099(09)70331-7.

2. Corrales-Medina VF, Musher DM, Shachkina S, Chirinos JA. Acute pneumonia and the cardiovascular system. Lancet. 2013;381:496-505. PMID:23332146, http://dx.doi.org/10.1016/S0140-6736(12)61266-5.

3. Viasus D, Garcia-Vidal C, Manresa F, Dorca J, Gudiol F, Carratalà J. Risk stratification and prognosis of acute cardiac events in hospitalized adults with community-acquired pneumonia. J Infect. 2013;66:27-33. PMID: 22981899, http://dx.doi.org/10.1016/j.jinf.2012.09.003.

4. Mortensen EM, Coley CM, Singer DE, Marrie TJ, Obrosky DS, Kapoor WN, et al. Causes of death for patients with community-acquired pneumonia: results from the Pneumonia Patient Outcomes Research Team cohort study. Arch Intern Med. 2002;162:1059-64. PMID:11996618, http://dx.doi.org/10. 1001/archinte.162.9.1059.

5. Kruger S, Frechen D. Cardiovascular complications and comorbidities in CAP. Eur Respir Monogr. 2014;63:256-65.

6. Peyrani P, Ramirez J. What is the association of cardiovascular events with clinical failure in patients with community-acquired pneumonia? Infect Dis Clin North Am. 2013;27:205-10. PMID:23398875, http://dx.doi.org/10.1016/j. idc.2012.11.010.

7. Spodick DH, Flessas AP, Johnson MM. Association of acute respiratory symptoms with onset of acute myocardial infarction: prospective investigation of 150 consecutive patients and matched control patients. Am J Cardiol. 1984;53:481-2. PMID:6695777, http://dx.doi.org/10.1016/00029149(84)90016-X.

8. Seedat MA, Feldman C, Skoularigis J, Promnitz DA, Smith C, Zwi S. A study of acute community-acquired pneumonia, including details of cardiac changes. Q J Med. 1993;86:669-75. PMID:8255965, http://dx.doi.org/10.1093/ qjmed/86.10.669.

9. Ramirez J, Aliberti S, Mirsaeidi M, Peyrani P, Filardo G, Amir A, et al. Acute myocardial infarction in hospitalized patients with community-acquired pneumonia. Clin Infect Dis. 2008;47:182-7. PMID:18533841, http://dx.doi.org/ $10.1086 / 589246$

10. Dutt TS, Tousheed SZ, Mohan BV. Community acquired pneumonia and cardiac diseases: a fatal association. Indian J Chest Dis Allied Sci. 2014;56: 153-6. PMID:25823109.

11. Mandal P, Chalmers JD, Choudhury G, Akram AR, Hill AT. Vascular complications are associated with poor outcome in community-acquired pneumonia. QJM. 2011;104:489-95. PMID:21217116, http://dx.doi.org/10. 1093/qjmed/hcq247.

12. Perry TW, Pugh MJ, Waterer GW, Nakashima B, Orihuela CJ, Copeland LA, et al. Incidence of cardiovascular events after hospital admission for pneumonia. Am J Med. 2011;124:244-51. PMID:21396508, http://dx.doi.org/ 10.1016/j.amjmed.2010.11.014.

13. Corrales-Medina VF, Musher DM, Wells GA, Chirinos JA, Chen L, Fine MJ. Cardiac complications in patients with community-acquired pneumonia: incidence, timing, risk factors, and association with short-term mortality. Circulation. 2012;125:773-81. PMID:22219349, http://dx.doi.org/10.1161/ CIRCULATIONAHA.111.040766.

14. Corrales-Medina VF, Taljaard M, Fine MJ, Dwivedi G, Perry JJ, Musher DM, et al. Risk stratification for cardiac complications in patients hospitalized for community-acquired pneumonia. Mayo Clin Proc. 2014;89:60-8. PMID: 24388023, http://dx.doi.org/10.1016/j.mayocp.2013.09.015.

15. Aliberti S, Ramirez J, Cosentini R, Valenti V, Voza A, Rossi P, et al. Acute myocardial infarction versus other cardiovascular events in community-acquired pneumonia. ERJ Open Res. 2015;1:00020-2015. http://dx.doi.org/10.1183/ 23120541.00020-2015.

16. Soto-Gomez N, Anzueto A, Waterer GW, Restrepo MI, Mortensen EM. Pneumonia: an arrhythmogenic disease? Am J Med. 2013;126:43-8. PMID: 23177550, http://dx.doi.org/10.1016/j.amjmed.2012.08.005.

17. Griffin AT, Wiemken TL, Arnold FW. Risk factors for cardiovascular events in hospitalized patients with community-acquired pneumonia. Int J Infect Dis. 2013;17:e1125-9. PMID:24007923, http://dx.doi.org/10.1016/j.ijid.2013.07.005.

18. Adamuz J, Viasus D, Jiménez-Martínez E, Isla P, Garcia-Vidal C, Dorca J, et al. Incidence, timing and risk factors associated with 1-year mortality after hospitalization for community-acquired pneumonia. J Infect. 2014;68:534-41. PMID:24534605, http://dx.doi.org/10.1016/j.jinf.2014.02.006.

19. Cangemi R, Calvieri C, Falcone M, Bucci T, Bertazzoni G, Scarpellini MG, SIXTUS Study Group. Relation of cardiac complications in the early phase of 
community-acquired pneumonia to long-term mortality and cardiovascular events. Am J Cardiol. 2015;116:647-51. PMID:26089009, http://dx.doi.org/10. 1016/j.amjcard.2015.05.028.

20. Corrales-Medina VF, Taljaard M, Yende S, Kronmal R, Dwivedi G, Newman $A B$, et al. Intermediate and long-term risk of new-onset heart failure after hospitalization for pneumonia in elderly adults. Am Heart J. 2015;170:306-12. PMID:26299228, http://dx.doi.org/10.1016/j.ahj.2015.04.028.

21. Corrales-Medina VF, Alvarez KN, Weissfeld LA, Angus DC, Chirinos JA, Chang CC, et al. Association between hospitalization for pneumonia and subsequent risk of cardiovascular disease. JAMA. 2015;313:264-74. PMID:25602997, http://dx.doi.org/10.1001/jama.2014.18229.

22. Rajas $\mathrm{O}$, Ortega-Gómez M, Galván Román JM, Curbelo J, Fernández Jiménez $G$, Vega Piris $L$, et al. The incidence of cardiovascular events after hospitalization due to CAP and their association with different inflammatory markers. BMC Pulm Med. 2014;14:197. PMID:25495677, http://dx.doi.org/10. 1186/1471-2466-14-197.

23. Lichtman JH, Fathi A, Radford MJ, Lin Z, Loeser CS, Krumholz HM. Acute, severe noncardiac conditions in patients with acute myocardial infarction. Am J Med. 2006;119:843-50. PMID:17000215, http://dx.doi.org/10.1016/j. amjmed.2006.03.040

24. Musher DM, Rueda AM, Kaka AS, Mapara SM. The association between pneumococcal pneumonia and acute cardiac events. Clin Infect Dis. 2007; 45:158-65. PMID:17578773, http://dx.doi.org/10.1086/518849.

25. Corrales-Medina VF, Suh KN, Rose G, Chirinos JA, Doucette S, Cameron DW, et al. Cardiac complications in patients with community-acquired pneumonia: a systematic review and meta-analysis of observational studies. PLoS Med. 2011;8:e1001048. PMID:21738449, http://dx.doi.org/10.1371/journal.pmed.1001048.

26. Bazaz R, Marriott HM, Francis SE, Dockrell DH. Mechanistic links between acute respiratory tract infections and acute coronary syndromes. J Infect. 2013:66:1-17. PMID:23046969, http://dx.doi.org/10.1016/j.jinf.2012.09.009.

27. Mirsaeidi M, Peyrani P, Aliberti S, Filardo G, Bordon J, Blasi F, et al. Thrombocytopenia and thrombocytosis at time of hospitalization predict mortality in patients with community-acquired pneumonia. Chest. 2010;137:416-20. PMID:19837825, http://dx.doi.org/10.1378/chest.09-0998.

28. Cangemi R, Casciaro M, Rossi E, Calvieri C, Bucci T, Calabrese CM, SIXTUS Study Group. Platelet activation is associated with myocardial infarction in patients with pneumonia. J Am Coll Cardiol. 2014;64:1917-25. PMID: 25444147, http://dx.doi.org/10.1016/j.jacc.2014.07.985

29. Rondina MT, Garraud O. Emerging evidence for platelets as immune and inflammatory effector cells. Front Immunol. 2014;5:653. PMID:25566264, http://dx.doi.org/10.3389/fimmu.2014.00653

30. Thomas MR, Storey RF. The role of platelets in inflammation. Thromb Haemost. 2015;114:449-58. PMID:26293514, http://dx.doi.org/10.1160/TH14-12-1067.

31. Feldman C, Anderson R. Community-acquired pneumonia: pathogenesis of acute cardiac events and potential adjunctive therapies. Chest. 2015;148: 523-32. PMID:25951315, http://dx.doi.org/10.1378/chest.15-0484.

32. Ed Rainger $G$, Chimen M, Harrison MJ, Yates CM, Harrison P, Watson SP, et al. The role of platelets in the recruitment of leukocytes during vascular disease. Platelets. 2015;26:507-20. PMID:26196409, http://dx.doi.org/10.3109/ 09537104.2015.1064881.

33. Kapur R, Zufferey A, Boilard E, Semple JW. Nouvelle cuisine: platelets served with inflammation. J Immunol. 2015;194:5579-87. PMID:26048965, http://dx. doi.org/10.4049/jimmunol.1500259.

34. Malley R, Henneke P, Morse SC, Cieslewicz MJ, Lipsitch M, Thompson CM, et al. Recognition of pneumolysin by Toll-like receptor 4 confers resistance to pneumococcal infection. Proc Natl Acad Sci USA. 2003;100:1966-71. PMID:12569171, http://dx.doi.org/10.1073/pnas.0435928100.

35. Parimon T, Li Z, Bolz DD, McIndoo ER, Bayer CR, Stevens DL, et al. Staphylococcus aureus a-hemolysin promotes platelet-neutrophil aggregate formation. J Infect Dis. 2013;208:761-70. PMID:23698812, http://dx.doi.org/ 10.1093/infdis/jit235.

36. Zhang $S$, Zhang S, Hu L, Zhai L, Xue R, Ye J, et al. Nucleotide-binding oligomerization domain 2 receptor is expressed in platelets and enhances platelet activation and thrombosis. Circulation. 2015;131:1160-70. PMID: 25825396, http://dx.doi.org/10.1161/CIRCULATIONAHA.114.013743.

37. De Stoppelaar SF, Claushuis TA, Jansen MP, Hou B, Roelofs JJ, Van't Veer C, et al. The role of platelet MyD88 in host response during gram-negative sepsis. J Thromb Haemost. 2015:13:1709-20. PMID:26178922, http://dx.doi. org/10.1111/jth.13048.

38. Arman M, Krauel K, Tilley DO, Weber C, Cox D, Greinacher A, et al. Amplification of bacteria-induced platelet activation is triggered by FcyRIIA, integrin allbß3, and platelet factor 4. Blood. 2014;123:3166-74. PMID: 24642751, http://dx.doi.org/10.1182/blood-2013-11-540526.

39. Anderson R, Nel JG, Theron AJ, Mitchell TJ, Feldman C. Pneumolysin triggers the production of platelet-activating factor production by human neutrophils in vitro. Thorax. 2015;70 Suppl 3:A49. http://dx.doi. org/10.1136/thoraxjnl-2015-207770.91.

40. Witzenrath M, Gutbier B, Owen JS, Schmeck B, Mitchell TJ, Mayer K, et al. Role of platelet-activating factor in pneumolysin-induced acute lung injury. Crit Care Med. 2007;35:1756-62. PMID:17522574, http://dx.doi.org/10.1097/ 01.CCM.0000269212.84709.23

41. Nel JG, Durandt C, Theron AJ, Mitchell TJ, Feldman C, Anderson R. Pneumolysin mediates platelet activation in vitro. Lung. 2016. http://dx.doi.org/10.1007/s00408-016-9900-5.

42. Page C, Pitchford S. Neutrophil and platelet complexes and their relevance to neutrophil recruitment and activation. Int Immunopharmacol. 2013:17: 1176-84. PMID:23810443, http://dx.doi.org/10.1016/j.intimp.2013.06.004.

43. Stakos DA, Kambas K, Konstantinidis T, Mitroulis I, Apostolidou E, Arelaki S, et al. Expression of functional tissue factor by neutrophil extracellular traps in culprit artery of acute myocardial infarction. Eur Heart J. 2015;36:1405-14 PMID:25660055, http://dx.doi.org/10.1093/eurheartj/ehv007.

44. Saffarzadeh M, Juenemann C, Queisser MA, Lochnit G, Barreto G, Galuska SP, et al. Neutrophil extracellular traps directly induce epithelial and endothelial cell death: a predominant role of histones. PLoS ONE. 2012;7:e32366. PMID: 22389696, http://dx.doi.org/10.1371/journal.pone.0032366.

45. Brown AO, Mann B, Gao G, Hankins JS, Humann J, Giardina J, et al. Streptococcus pneumoniae translocates into the myocardium and forms unique microlesions that disrupt cardiac function. PLoS Pathog. 2014;10: e1004383. PMID:25232870, http://dx.doi.org/10.1371/journal.ppat.1004383.

46. Alhamdi Y, Neill DR, Abrams ST, Malak HA, Yahya R, Barrett-Jolley R, et al. Circulating pneumolysin is a potent inducer of cardiac injury during pneumococcal infection. PLoS Pathog. 2015;11:e1004836. PMID:25973949, http://dx.doi.org/10.1371/journal.ppat.1004836.

47. Cockeran R, Theron AJ, Steel HC, Matlola NM, Mitchell TJ, Feldman C, et al. Proinflammatory interactions of pneumolysin with human neutrophils. J Infect Dis. 2001;183:604-11. PMID:11170986, http://dx.doi.org/10.1086/318536.

48. Akinosoglou K, Alexopoulos D. Use of antiplatelet agents in sepsis: a glimpse into the future. Thromb Res. 2014;133:131-8. PMID:24103487, http://dx.doi.org/10.1016/j.thromres.2013.07.002.

49. Falcone M, Russo A, Cangemi R, Farcomeni A, Calvieri C, Barillà F, et al. Lower mortality rate in elderly patients with community-onset pneumonia on treatment with aspirin. J Am Heart Assoc. 2015;4:e001595. PMID: 25564372, http://dx.doi.org/10.1161/JAHA.114.001595.

50. Winning J, Reichel J, Eisenhut Y, Hamacher J, Kohl M, Deigner HP, et al. Anti-platelet drugs and outcome in severe infection: clinical impact and underlying mechanisms. Platelets. 2009:20:50-7. PMID:19172522, http://dx. doi.org/10.1080/09537100802503368.

51. O'Neal Jr HR, Koyama T, Koehler EA, Siew E, Curtis BR, Fremont RD, et al. Prehospital statin and aspirin use and the prevalence of severe sepsis and acute lung injury/acute respiratory distress syndrome. Crit Care Med. 2011 39:1343-50. PMID:21336116, http://dx.doi.org/10.1097/CCM. Ob013e3182120992.

52. Erlich JM, Talmor DS, Cartin-Ceba R, Gajic O, Kor DJ. Prehospitalization antiplatelet therapy is associated with a reduced incidence of acute lung injury: a population-based cohort study. Chest. 2011;139:289-95. PMID: 20688925, http://dx.doi.org/10.1378/chest.10-0891.

53. Harr JN, Moore EE, Johnson J, Chin TL, Wohlauer MV, Maier R, et al. Antiplatelet therapy is associated with decreased transfusion-associated risk of lung dysfunction, multiple organ failure, and mortality in trauma patients. Crit Care Med. 2013;41:399-404. PMID:23263579, http://dx.doi.org/10.1097/ cCM.0b013e31826ab38b.

54. Kor DJ, Erlich J, Gong MN, Malinchoc M, Carter RE, Gajic O, U.S. Critical IIIness and Injury Trials Group. Lung Injury Prevention Study Investigators. Association of prehospitalization aspirin therapy and acute lung injury: results of a multicenter international observational study of at-risk patients. Crit Care Med. 2011;39:2393-400. PMID:21725238, http://dx.doi.org/10.1097/ CCM.0b013e318225757f.

55. Boyle AJ, Di Gangi S, Hamid UI, Mottram LJ, McNamee L, White G, et al. Aspirin therapy in patients with acute respiratory distress syndrome (ARDS) is associated with reduced intensive care unit mortality: a prospective analysis. Crit Care. 2015;19:109. PMID:25887566, http://dx.doi.org/10.1186/ s13054-015-0846-4. 
56. Feldman C, Munro NC, Jeffery PK, Mitchell TJ, Andrew PW, Boulnois GJ, et al. Pneumolysin induces the salient histologic features of pneumococcal infection in the rat lung in vivo. Am J Respir Cell Mol Biol. 1991;5:416-23. PMID:1834101, http://dx.doi.org/10.1165/ajrcmb/5.5.416.

57. García-Suárez MM, Flórez N, Astudillo A, Vázquez F, Villaverde R, Fabrizio K, et al. The role of pneumolysin in mediating lung damage in a lethal pneumococcal pneumonia murine model. Respir Res. 2007;8:3. PMID: 17257395, http://dx.doi.org/10.1186/1465-9921-8-3.

58. Anderson R, Tintinger G, Cockeran R, Potjo M, Feldman C. Beneficial and harmful interactions of antibiotics with microbial pathogens and the host innate immune system. Pharmaceuticals (Ott). 2010;3:1694-710. http://dx. doi.org/10.3390/ph3051694.

59. Anderson R, Steel HC, Cockeran R, Smith AM, von Gottberg A, de Gouveia L, et al. Clarithromycin alone and in combination with ceftriaxone inhibits the production of pneumolysin by both macrolide-susceptible and macrolide-resistant strains of Streptococcus pneumoniae. J Antimicrob Chemother. 2007;59:224-9. PMID:17218449, http://dx.doi.org/10.1093/jac/dkl479.

60. Anderson R, Steel HC, Cockeran R, von Gottberg A, de Gouveia L, Klugman $K P$, et al. Comparison of the effects of macrolides, amoxicillin, ceftriaxone, doxycycline, tobramycin and fluoroquinolones, on the production of pneumolysin by Streptococcus pneumoniae in vitro. J Antimicrob Chemother. 2007;60:1155-8. PMID:17848373, http://dx.doi.org/10.1093/jac/dkm338.

61. Cockeran R, Steel HC, Wolter N, de Gouveia L, von Gottberg A, Klugman KP, et al. Effects of clarithromycin at sub-minimum inhibitory concentrations on early erm(B)-expressing macrolide-resistant strain of Streptococcus pneumoniae. Open J Respir Dis. 2012;2:1-8. http://dx.doi.org/10.4236/ojrd. 2012.21001.

62. Steel HC, Theron AJ, Cockeran R, Anderson R, Feldman C. Pathogen- and host-directed anti-inflammatory activities of macrolide antibiotics. Mediators Inflamm. 2012;2012:584262. PMID:22778497, http://dx.doi.org/10.1155/ 2012/584262.

63. Rosch JW, Boyd AR, Hinojosa E, Pestina T, Hu Y, Persons DA, et al. Statins protect against fulminant pneumococcal infection and cytolysin toxicity in a mouse model of sickle cell disease. J Clin Invest. 2010;120:627-35. PMID: 20093777, http://dx.doi.org/10.1172/JCl39843.

64. Statt S, Ruan JW, Hung LY, Chang CY, Huang CT, Lim JH et al. Statinconferred enhanced cellular resistance against bacterial pore-forming toxins in airway epithelial cells. Am J Respir Cell Mol Biol 2015 Advance online publication. http://dx.doi.org/10.1165/rcmb.2014-03910C.

65. Henry BD, Neill DR, Becker KA, Gore S, Bricio-Moreno L, Ziobro R, et al. Engineered liposomes sequester bacterial exotoxins and protect from severe invasive infections in mice. Nat Biotechnol. 2015;33:81-8. PMID 25362245, http://dx.doi.org/10.1038/nbt.3037.

66. Siriwardena AN, Asghar Z, Coupland CC. Influenza and pneumococcal vaccination and risk of stroke or transient ischaemic attack-matched case control study. Vaccine. 2014;32:1354-61. PMID:24486370, http://dx.doi.org/ 10.1016/j.vaccine.2014.01.029

67. Vila-Corcoles A, Ochoa-Gondar O, Rodriguez-Blanco T, de Diego-Cabanes C, Satue-Gracia E, Vila-Rovira A, EPIVAC Research Group. Evaluating clinical effectiveness of pneumococcal vaccination in preventing stroke: the CAPAMIS Study, 3-year follow-up. J Stroke Cerebrovasc Dis. 2014;23:157784. PMID:24656243, http://dx.doi.org/10.1016/j.jstrokecerebrovasdis.2013.12. 047.

68. Davis MM, Taubert K, Benin AL, Brown DW, Mensah GA, Baddour LM, et al. American Heart Association; American College of Cardiology. Influenza vaccination as secondary prevention for cardiovascular disease: a science advisory from the American Heart Association/American College of Cardiology. Circulation. 2006;114:1549-53. PMID:16982936, http://dx.doi.org/ 10.1161/CIRCULATIONAHA.106.178242.

69. Vila-Córcoles A. Vaccinate your child and save its grandparents from a heart attack? Current perspectives in antipneumococcal vaccination. J Intern Med. 2009;266:432-44. PMID:19754854, http://dx.doi.org/10.1111/j. 1365-2796.2009.02149.x.

70. Lamontagne F, Garant MP, Carvalho JC, Lanthier L, Smieja M, Pilon D. Pneumococcal vaccination and risk of myocardial infarction. CMAJ. 2008; 179:773-7. PMID:18838452, http://dx.doi.org/10.1503/cmaj.070221.

71. Vlachopoulos CV, Terentes-Printzios DG, Aznaouridis KA, Pietri PG, Stefanadis $\mathrm{Cl}$. Association between pneumococcal vaccination and cardiovascular outcomes: a systematic review and meta-analysis of cohort studies. Eur J Prev Cardiol. 2015;22:1185-99. PMID:25252595, http://dx.doi.org/10.1177/ 2047487314549512.
72. Tseng HF, Slezak JM, Quinn VP, Sy LS, Van den Eeden SK, Jacobsen SJ. Pneumococcal vaccination and risk of acute myocardial infarction and stroke in men. JAMA. 2010;303:1699-706. PMID:20442385, http://dx.doi.org/ 10.1001/jama.2010.529.

73. Ochoa-Gondar O, Vila-Corcoles A, Rodriguez-Blanco T, de Diego-Cabanes C, Hospital-Guardiola I, Jariod-Pamies M, EPIVAC Research Group. Evaluating the clinical effectiveness of pneumococcal vaccination in preventing myocardial infarction: The CAPAMIS study, three-year follow-up. Vaccine. 2014;32:252-7. PMID:24262314, http://dx.doi.org/10.1016/j.vaccine.2013.11.017.

74. Eurich DT, Johnstone JJ, Minhas-Sandhu JK, Marrie TJ, Majumdar SR. Pneumococcal vaccination and risk of acute coronary syndromes in patients with pneumonia: population-based cohort study. Heart. 2012;98:1072-7. PMID:22739637, http://dx.doi.org/10.1136/heartjnl-2012-301743.

75. Hung IF, Leung AY, Chu DW, Leung D, Cheung T, Chan CK, et al. Prevention of acute myocardial infarction and stroke among elderly persons by dual pneumococcal and influenza vaccination: a prospective cohort study. Clin Infect Dis. 2010;51:1007-16. PMID:20887208, http://dx.doi.org/10.1086/656587.

76. Bonten MJ, Huijts SM, Bolkenbaas M, Webber C, Patterson S, Gault S, et al. Polysaccharide conjugate vaccine against pneumococcal pneumonia in adults. N Engl J Med. 2015;372:1114-25. PMID:25785969, http://dx.doi.org/ 10.1056/NEJMoa1408544.

77. Feldman C, Anderson R. Review: current and new generation pneumococcal vaccines. J Infect. 2014;69:309-25. PMID:24968238, http://dx.doi.org/10.1016/j. jinf.2014.06.006.

\section{Submit your next manuscript to BioMed Central and we will help you at every step:}

- We accept pre-submission inquiries

- Our selector tool helps you to find the most relevant journal

- We provide round the clock customer support

- Convenient online submission

- Thorough peer review

- Inclusion in PubMed and all major indexing services

- Maximum visibility for your research

Submit your manuscript at www.biomedcentral.com/submit
C Biomed Central 